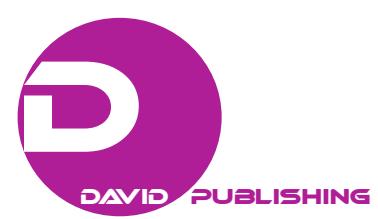

\title{
An Evaluation of Game Theory With the Value Cluster Model in Logistics Service Providers
}

\author{
Chumpol Saichuer, Sataporn Amornsawadwatana, Wanchai Rattanawong \\ University of the Thai Chamber of Commerce, Bangkok, Thailand
}

\begin{abstract}
Sole traders and other small businesses sometimes work together co-operatively to enhance their trade through joint activities such as purchasing and marketing. This approach, known as a co-operative consortium, can save money, spread risk, and enable the participating businesses to pool their resources, provide mutual support and learning and strengthen their business sector, while maintaining their business independence. In the logistics industry, value cluster may concern with Third Party Logistics Providers (3PLs). 3PLs are those entities that arrange shipments, as well as manage and provide advice on transportation and transportation-related services for shippers, freight carriers, and other related entities. 3PLs may include brokers, freight forwarders, rail transporters, consolidators, shippers, and air cargo agents. The logistics industry is changing rapidly due to the combination of a de-regulated transportation environment, together with 3PLs embracing the internet, e-commerce and other electronic means to provide their logistics services. To verify mutual benefit between two parties or in one cluster, game theory is used as a major method in mathematical economics and business for modeling competing behaviors of interacting agents. This research presents a proposed value cluster model in logistics service providers with game theory. It is an attempt to develop a new model to support a theory of partners' model and game theory model in accompanied with various supporting concepts such as transportation, freight transportation, distribution, warehouse, custom procedure, and sourcing defined by this thesis. A process of developing, rationale behind, and explanation of the components on the model are described. The model has been developed throughout the period of this research study, and its components focus on the context of value cluster in logistics service providers as independent variables that reflect dependent variables used in an exemplary case study. The last section is a review and brief conclusion of the model. The objectives of this research are: 1) to investigate mutual benefit of logistics service providers cluster, 2) to propose the model of value cluster in logistics service providers, and 3) to quantify the value cluster model using the game theory that provide a mathematical description of a social situation in which two or more individuals, or players interact.
\end{abstract}

Keywords: mutual benefit, logistics service providers, cluster, game theory

Chumpol Saichuer, Ph.D. student in logistics, School of Engineering, University of the Thai Chamber of Commerce, Bangkok, Thailand.

Sataporn Amornsawadwatana, assoc. prof., Dr., Department of Logistics Engineering, School of Engineering, University of the Thai Chamber of Commerce, Bangkok, Thailand.

Wanchai Rattanawong, assoc. prof., Dr., Department of Logistics Engineering, School of Engineering, University of the Thai Chamber of Commerce, Bangkok, Thailand.

Correspondence concerning this article should be addressed to Chumpol Saichuer, School of Engineering, University of the Thai Chamber of Commerce, Vibhavadee-Rangsit Road, Dindaeng, Bangkok, 10400, Thailand. 


\section{Introduction}

Sole traders and other small businesses sometimes work together co-operatively to enhance their trade through joint activities such as purchasing and marketing. This approach, known as a co-operative consortium, can save money, spread risk, and enable the participating businesses to pool their resources, provide mutual support and learning, and strengthen their business sector, while maintaining their business independence. Benefit societies can be organized around a shared ethnic background, religion, occupation, geographical region, or other basis. Benefits may include money or assistance for sickness, retirement, education, birth of a baby, funeral and medical expenses, and unemployment. Often benefit societies provide a social or educational framework for members and their families to support each other and contribute to the wider community.

Examples of benefit societies include trade unions, friendly societies, credit unions, self-help groups, landsmanshaftn, immigrant hometown societies, fraternal organizations such as freemasons and odd fellows, coworking communities, and many others. Peter Kropotkin posited early in the 20th century that mutual aid affiliations predate human culture and are as much a factor in evolution as is survival of the fittest. A benefit society can be characterized by: 1) members having equivalent opportunity for a say in the organization, 2) members having potentially equivalent benefits, 3) aid would go to those in need (strong helping the weak), 4) collection fund for payment of benefits, 5) educating others about a group’s interest, 6) preserving cultural traditions, and 7) mutual defense.

In the logistics industry, value cluster may concern with Third Party Logistics Providers (3PLs). A third-party logistics provider (abbreviated 3PL, or sometimes TPL) is a firm that provides a one stop shop service to its customers of outsourced (or "third party") logistics services for part, or all of their supply chain management functions. Third party logistics providers typically specialize in integrated operation, warehousing, and transportation services that can be scaled and customized to customer's needs based on market conditions and the demands and delivery service requirements for their products and materials. A 3PL is an operator, which specializes in integrated operation, warehousing, and transportation services. These services may be $100 \%$ outsourced, as in the case of "non-asset based 3PL". It is then a pure 3PL. It may also own part of its operations, such as warehouses, vans, or trucks. It then is both a 3PL and a 2PL, but is usually still called a 3PL. It can also offer genuine supply chain consulting services outside of its usual range of services. It is then both a 3PL and a 4PL, but is usually still called a 3PL. It is important to differentiate 3PL, which actually deliver supply chain consulting services outside of their usual range of integrated operations, from 3PL which use the term consulting or 4PL abusively, as a marketing tool only. Some 3PLs currently go as far as giving a title of consultant to their sales people, who are only selling their classical 3PL services (Wikipedia, 2010).

To verify mutual benefit between two parties or in one cluster, game theory is used as a major method in mathematical economics and business for modeling competing behaviors of interacting agents. The objectives of this research are: 1) to investigate mutual benefit of logistics service providers cluster, 2) to propose the model of value cluster in logistics service providers, and 3) to quantify the value cluster model using the game theory that provides a mathematical description of a social situation in which two or more individuals, or players, interact. Such a broad scope allows many kinds of models. There may be two players or more. The players may be competitive or cooperative. With more than two players there may be collusion among subsets of the players. Games may involve several sequential steps or one step for each player. Competitive situations may be repeated or be faced only once. Information concerning the rules of engagement and the payoffs may be known to all 
players or imperfectly known to some. In an introductory discussion, it touched on this important and valuable subject. This study restricts attention to the simplest model: the two-person and zero-sum game.

\section{Literature Review}

\section{Supply Chain Management}

A supply chain is a system of organizations, people, technology, activities, information, and resources involved in moving a product or service from supplier to customer. Supply chain activities transform natural resources, raw materials, and components into a finished product that is delivered to the end customer. Sophisticated supply chain systems used products that may re-enter the supply chain at any point where residual value is recyclable. Supply chains link value chains. In the 1980s, the term Supply Chain Management (SCM) was developed to express the need to integrate the key business processes, from end user through original suppliers. Original suppliers provide products, services, and information that add value for customers and other stakeholders. The basic idea behind the SCM is that companies and corporations involve themselves in a supply chain by exchanging information regarding market fluctuations and production capabilities. If all relevant information is accessible to any relevant company, every company in the supply chain has the ability to help optimize the entire supply chain rather than sub optimize based on a local interest. This will lead to better planned overall production and distribution which can cut costs and give a more attractive final product leading to better sales and better overall results for the companies involved. Incorporating SCM successfully leads to a new kind of competition on the global market where competition is no longer of the company versus company form but rather takes on a supply chain versus supply chain form.

The primary objective of supply chain management is to fulfill customer's demands through the most efficient use of resources, including distribution capacity, inventory, and labor. In theory, a supply chain seeks to match demand with supply and do so with the minimal inventory. Various aspects of optimizing the supply chain include liaising with suppliers to eliminate bottlenecks; sourcing strategically to strike a balance between the lowest material cost and transportation, implementing JIT (Just in Time) techniques to optimize manufacturing flow; maintaining the right mix and location of factories and warehouses to serve customer markets, and using location/allocation, vehicle routing analysis, dynamic programming, and of course, traditional logistics optimization to maximize the efficiency of the distribution side. There is often confusion over the terms supply chain and logistics. It is now generally accepted that the term "logistics" applies to activities within one company/organization involving distribution of product whereas the term supply chain also encompasses manufacturing and procurement and therefore has a much broader focus as it involves multiple enterprises, including suppliers, manufacturers, and retailers working together to meet a customer's need for a product or service. Starting in the 1990s, several companies chose to outsource the logistics aspect of supply chain management by partnering with a 3PL, third-party logistics provider. Companies also outsource production to contract manufacturers. Technology companies have risen to meet the demand to help manage these complex systems.

\section{Transportation/Freight/Warehouse}

Transportation. Transport or transportation is the movement of people, animals, and goods from one location to another. Modes of transport include air, rail, road, water, cable, pipeline, and space. The field can be divided into infrastructure, vehicles, and operations. Transport is important since it enables trade between peoples, 
which in turn establishes civilizations. Transport infrastructure consists of the fixed installations necessary for transport, and may be roads, railways, airways, waterways, canals and pipelines, and terminals such as airports, railway stations, bus stations, warehouses, trucking terminals, refueling depots (including fueling docks and fuel stations), and seaports. Terminals may be used both for interchange of passengers and cargo for maintenance. Vehicles traveling on these networks may include automobiles, bicycles, buses, trains, trucks, people, helicopters, and aircraft. Operations deal with the way the vehicles are operated, and the procedures are set for this purpose including financing, legalities, and policies. In the transport industry, operations and ownership of infrastructure can be either public or private, depending on the country and mode. Passenger transport may be public, where operators provide scheduled services, or private. Freight transport has become focused on containerization, although bulk transport is used for large volumes of durable items. Transport plays an important part in economic growth and globalization, but most types cause air pollution and use a large amount of land. While it is heavily subsidized by governments, good planning of transport is essential to make traffic flow, and restrain urban sprawl.

Freight. Freight transport, or shipping, is a key in the value chain in manufacturing. With increased specialization and globalization, production is being located further away from consumption, rapidly increasing the demand for transport. While all modes of transport are used for cargo transport, there is high differentiation between the nature of the cargo transports in which mode is chosen. Logistics refers to the entire process of transferring products from producer to consumer, including storage, transport, transshipment, warehousing, material-handling, and packaging with associated exchange of information. Incoterm deals with the handling of payment and responsibility of risk during transport. Containerization, with the standardization of ISO containers on all vehicles and at all ports, has revolutionized international and domestic trade, offering huge reduction in transshipment costs. Traditionally, all cargos had to be manually loaded and unloaded into the haul of any ship or car; containerization allows for automated handling and transfer between modes, and the standardized sizes allow for gains in economy of scale in vehicle operation. This has been one of the key driving factors in international trade and globalization since the 1950s. Bulk transport is common with cargo that can be handled roughly without deterioration; typical examples are ore, coal, cereals, and petroleum. Because of the uniformity of the product, mechanical handling can allow enormous quantities to be handled quickly and efficiently. The low value of the cargo combined with high volume also means that economies of scale become essential in transport, and gigantic ships and whole trains are commonly used to transport bulk. Liquid products with sufficient volume may also be transported by pipeline. Air freight has become more common for products of high value; while less than one percent of world transport by volume is by airline, it amounts to 40 percent of the value. Time has become especially important in regards to principles such as postponement and just-in-time within the value chain, resulting in a high willingness to pay for quick delivery of key components or items of high value-to-weight ratio. In addition to mail, common items sent by air include electronics and fashion clothing.

Warehouse. A warehouse is a commercial building for storage of goods. Warehouses are used by manufacturers, importers, exporters, wholesalers, transport businesses, customs, etc. They are usually large plain buildings in industrial areas of cities and towns and villages. They usually have loading docks to load and unload goods from trucks. Sometimes, warehouses are designed for the loading and unloading of goods directly from railways, airports, or seaports. They often have cranes and forklifts for moving goods, which are usually placed on ISO standard pallets loaded into pallet racks. Stored goods can include any raw materials, packing materials, spare parts, components, or finished goods associated with agriculture, manufacturing, or commerce. 


\section{Mutual Benefit/Relationship}

A relationship is normally viewed as a connection between individuals, such as a romantic or intimate relationship, or a parent-child relationship. Individuals can also have relationships with groups of people, such as the relation between a pastor and his congregation, an uncle and a family, or a mayor and a town. Finally, groups or even nations may have relations with each other, though this there is a much broader domain than that covered under the topic of interpersonal relationships. Most scholarly work on relationships focuses on the small subset of interpersonal relationships involving romantic partners in pairs or dyads. Interpersonal relationships usually involve some level of interdependence. People in a relationship tend to influence each other, share their thoughts and feelings, and engage in activities together. Because of this interdependence, most things that change or impact one member of the relationship will have some level of impact on the other member. Interpersonal relationships are dynamic systems that change continuously during their existence. One of the most influential models of relationship development was proposed by psychologist Levinger (1983). This model was formulated to describe heterosexual, adult romantic relationships, but it has been applied to other kinds of interpersonal relations as well. According to the model, the natural development of a relationship follows five stages:

1. Acquaintance - It depends on previous relationships, physical proximity, first impressions, and a variety of other factors. If two people begin to like each other, continued interactions may lead to the next stage, but acquaintance can continue indefinitely.

2. Buildup-During this stage, people begin to trust and care about each other. The need for intimacy, compatibility and such filtering agents as common background and goals will influence whether or not interaction continues.

3. Continuation-This stage follows a mutual commitment to a long-term friendship, romantic relationship, or marriage. It is generally a long, relative stable period. Nevertheless, continued growth and development will occur during this time. Mutual trust is important for sustaining the relationship.

4. Deterioration-Not all relationships deteriorate, but those that do tend to show signs of trouble. Boredom, resentment, and dissatisfaction may occur, and individuals may communicate less and avoid self-disclosure. Loss of trust and betrayals may take place as the downward spiral continues, eventually ending the relationship. (Alternately, the participants may find some ways to resolve the problems and reestablish trust.)

5. Termination-The final stage marks the end of the relationship, either by death in the case of a healthy relationship, or by separation.

\section{Game Theory}

Game theory is a study of strategic decision making. More formally, it is "the study of mathematical models of conflict and cooperation between intelligent rational decision-makers". An alternative term suggested "as a more descriptive name for the discipline” is interactive decision theory. Game theory is mainly used in economics, political science, and psychology, as well as logic and biology. The subject first addressed zero-sum games, such that one person's gains exactly equal net losses of the other participant(s). Today, however, game theory applies to a wide range of class relations, and has developed into an umbrella term for the logical side of science, to include both human and non-humans, like computers. Classic uses include a sense of balance in numerous games, where each person has found or developed a tactic that cannot successfully better his results, and give the other approaches. Modern game theory began with the idea regarding the existence of mixed-strategy equilibria in two-person zero-sum games and its proof by John von Neumann. Von Neumann's original proof 
used Brouwer's fixed-point theorem on continuous mappings into compact convex sets, which became a standard method in game theory and mathematical economics. Game theory has been widely recognized as an important tool in many fields. Eight game-theorists have won the Nobel Memorial Prize in economic sciences, and John Maynard Smith was awarded the Crafoord Prize for his application of game theory to biology.

Game theory is a major method used in mathematical economics and business for modeling competing behaviors of interacting agents. Applications include a wide array of economic phenomena and approaches, such as auctions, bargaining, mergers \& acquisitions pricing, fair division, duopolies, oligopolies, social network formation, agent-based computational economics, general equilibrium, mechanism design, and voting systems, and across such broad areas as experimental economics, behavioral economics, information economics, industrial organization, and political economy. This research usually focuses on particular sets of strategies known as equilibria in games. These "solution concepts" are usually based on what is required by norms of rationality. In non-cooperative games, the most famous one of these is the Nash equilibrium. A set of strategies is Nash equilibrium if each represents the best response to the other strategies. So, if all the players are playing the strategies in Nash equilibrium, they have no unilateral incentive to deviate, since their strategy is the best they can do given what others are doing. The payoffs of the game are generally taken to represent the utility of individual players. Often in modeling situations the payoffs represent money, which presumably corresponds to an individual's utility. This assumption, however, can be faulty. A prototypical paper on game theory in economics begins by presenting a game that is an abstraction of a particular economic situation. One or more solution concepts are chosen, and the author demonstrates which strategy sets in the presented game are equilibria of the appropriate type. Naturally, one might wonder what use should this information be put. Economists and business professors suggest two primary uses (noted above): descriptive and prescriptive.

For the context of cooperative game and non-cooperative game, a game is cooperative if the players are able to form binding commitments. For instance the legal system requires them to adhere to their promises. In noncooperative games this is not possible. Often it is assumed that communication among players is allowed in cooperative games, but not in noncooperative ones. However, this classification on two binary criteria has been questioned, and sometimes rejected (Harsanyi, 1974). Of the two types of games, noncooperative games are able to model situations to the finest details, producing accurate results. Cooperative games focus on the game at large. Considerable efforts have been made to link the two approaches. The so-called Nash-programme (clarification needed) has already established many of the cooperative solutions as noncooperative equilibria. Hybrid games contain cooperative and non-cooperative elements. For instance, coalitions of players are formed in a cooperative game, but these play in a non-cooperative fashion.

Furthermore, zero-sum games are a special case of constant-sum games, in which choices by players can neither increase nor decrease the available resources. In zero-sum games, the total benefit to all players in the game, for every combination of strategies, always adds to zero (more informally, a player benefits only at the equal expense of others). Poker exemplifies a zero-sum game (ignoring the possibility of the house's cut), because one wins exactly the amount one's opponents lose. Other zero-sum games include matching pennies and most classical board games including go and chess. Many games studied by game theorists (including the infamous prisoner's dilemma) are non-zero-sum games, because the outcome has net results greater or less than zero. Informally, in non-zero-sum games, a gain by one player does not necessarily correspond with a loss by another. Constant-sum games correspond to activities like theft and gambling, but not to the fundamental economic situation in which there are potential gains from trade. It is possible to transform any game into a 
(possibly asymmetric) zero-sum game by adding an additional dummy player (often called "the board"), whose losses compensate the players' net winnings.

\section{Process of Developing the Model}

The model developed in this research study is named as "the Value Cluster Model in Logistics Service Providers with Game Theory”. Figure 1 shows the logic of the process of development. The process started from a concept based on previous models and identified the factors used for cluster value concepts such as mutual benefit, relationship, and satisfaction of logistics service providers.

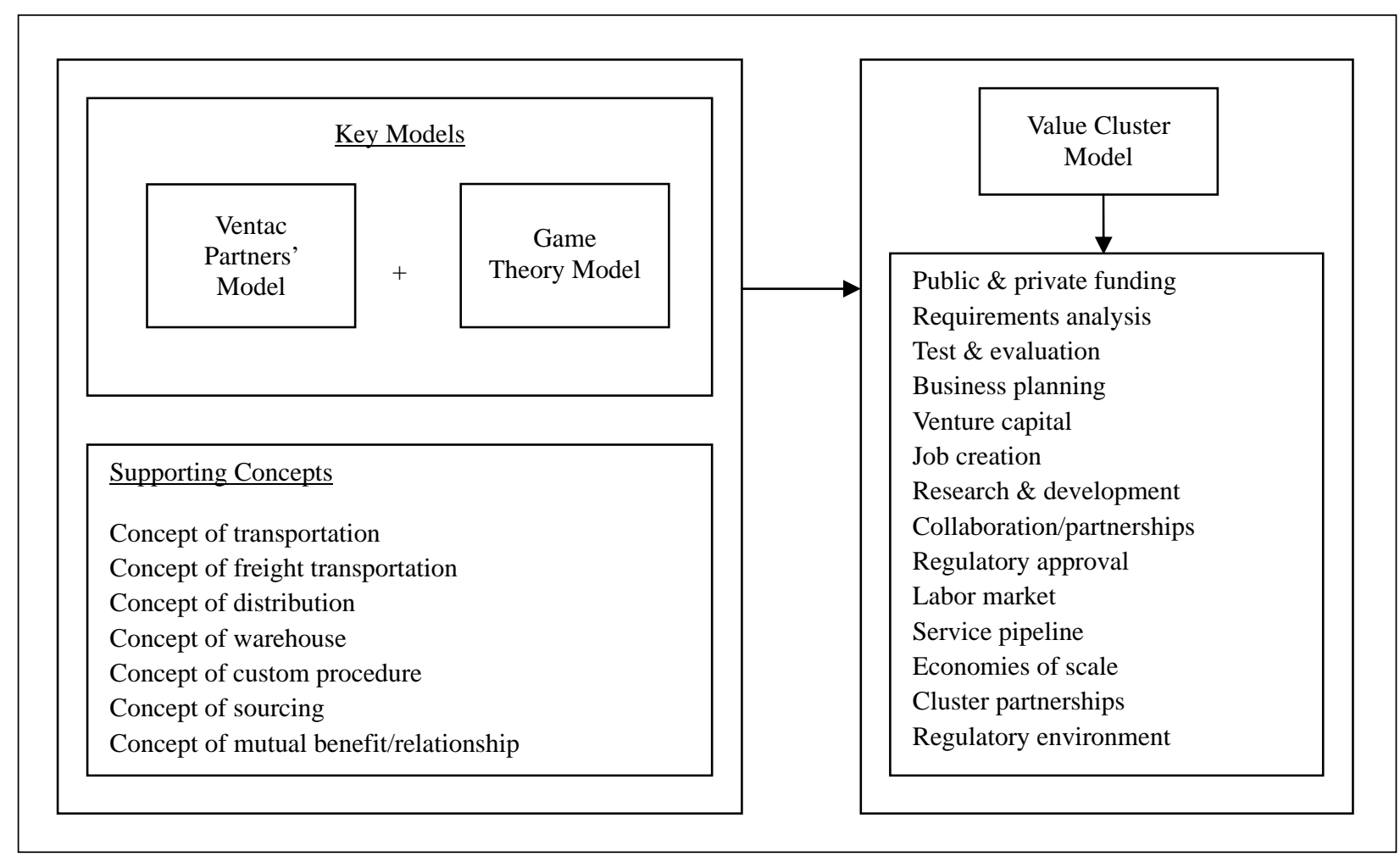

Figure 1. Development of the model.

This model was mainly based on the value cluster (Ventac Partners, 2011), its value proposition consists of a cluster of three parts: choice of target customer segments, particular focal combination of customer-driven benefits, and rational for why this firm and its partners can deliver the value cluster in a significantly better way than competitors. Therefore, the firm can serve multiple groups of customers with different value propositions. Another model is based on the game theory models proposed by several economists and philosophers such as Aumann and Shapley (1974), Cournot (1838), Edgeworth (1881), Farquharson (1969), Luce and Raiffa (1957), Duncan Luce and Raiffa (1989), Maynard Smith (1982), Maynard Smith and Price (1973), Nash (1950), Shapley (1953), von Neumann (1928), and Zermelo (1913). However, the independent models mentioned earlier were described and intended to provide general ideas of the relationship between each factor, and to support a conceptual framework of the Cluster Value Model in logistics service providers. Therefore, this research proposes a model of value cluster that may help logistics service providers to effectively manage their operation and business illustrated in Figure 2. 
Knowledge Creation

$\mid$

Requirements
analysis
Public \& Private
funding
Regulatory
environment
Cluster partnerships

Economies of scale
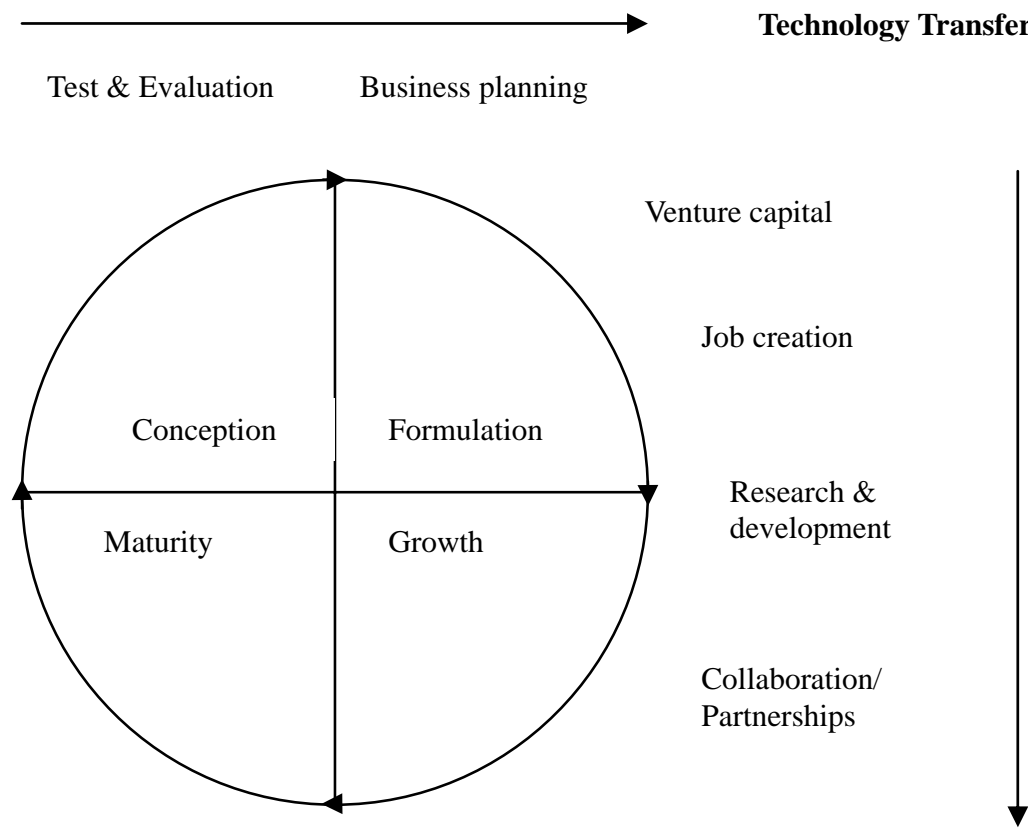

Regulatory approval

Service pipeline Labor market

Cluster \& Networks

\section{Commercialization}

\section{Payoff Matrix}

\section{Player II}

\begin{tabular}{|l|l|l|l|l|}
\hline & 1 & 2 & $\ldots$ & $n$ \\
\hline 1 & $P_{11}$ & $P_{12}$ & $\ldots$ & $P_{1 n}$ \\
\hline 2 & $P_{21}$ & $P_{22}$ & $\ldots$ & $P_{2 n}$ \\
\hline$\cdot$ &. & & & $\cdot$ \\
. &. & & &. \\
\hline$m$ & $\cdot$ & $P_{m 2}$ & $\ldots$ & $P_{m n}$ \\
\hline
\end{tabular}

Figure 2. Value Cluster Model in logistics service providers with game theory.

\section{Description of the Components on the Model}

\section{Internal Factors}

Public \& private funding. The public fund is used to account for education activities, district instruction and student support programs, general and administration expenditures, normal operations and maintenance, and state approved school district expenditures not specifically designated to be accounted for in any other fund. Private funding is from a particular company who has decided to fund a project or an event. You see that with athletes and race car drivers a lot. Those private companies are supporting them. The person may have more than one company or support them at a time and usually, those companies' advertise someway like with their names on the cars. 
Requirements analysis. Requirements analysis in systems engineering and software engineering encompasses those tasks that go into determining the needs or conditions to meet for a new or altered product, taking account of the possibly conflicting requirements of the various stakeholders, such as beneficiaries or users. It is an early stage in the more general activity of requirements engineering which encompasses all activities concerned with eliciting, analyzing, documenting, validating, and managing software or system requirements. Requirements analysis is critical to the success of a systems or software project. The requirements should be documented, actionable, measurable, testable, traceable, related to identified business needs or opportunities, and defined to a level of detail sufficient for system design.

Test and evaluation. Test and Evaluation is the process by which a system or components are compared against requirements and specifications through testing. The results are evaluated to assess progress of design, performance, supportability, etc. Developmental test and evaluation is an engineering tool used to reduce risk throughout the defense acquisition cycle. Operational test and evaluation is the actual or simulated employment by typical users of a system under realistic operational conditions.

Business planning. A business plan is a formal statement of a set of business goals, the reasons they are believed attainable, and the plan for reaching those goals. It may also contain background information about the organization or team attempting to reach those goals. Business plans may also target changes in perception and branding by the customer, client, taxpayer, or larger community. When the existing business is to assume a major change or when planning a new venture, a three to five years' business plan is required, since investors will look for their annual return in that timeframe.

Venture capital. Venture capital (VC) is financial capital provided to early-stage, high-potential, high risk, and growth startup companies. The venture capital fund makes money by owning equity in the companies it invests in, which usually have a novel technology or business model in high technology industries, such as biotechnology, IT, software, etc. The typical venture capital investment occurs after the seed funding round as growth funding round (also referred to as Series A round) in the interest of generating a return through an eventual realization event, such as an IPO or trade sale of the company. Venture capital is a subset of private equity. Therefore, all venture capital is private equity, but not all private equity is venture capital.

Job creation. Job creation programs are programs or projects undertaken by a government of a nation to assist unemployed members of the population in securing employment. As a cornerstone of Keynesian economics, they are especially common during time of high unemployment. They may either concentrate on macroeconomic policy in order to increase the supply of jobs, or create more efficient means to pair employment seekers with their prospective employers.

Research and development. The term R\&D or research and development refers to a specific group of activities within a business. The activities that are classified as R\&D differ from company to company, but there are two primary models. In one model, the primary function of an R\&D group is to develop new products; in the other model, the primary function of an R\&D group is to discover and create new knowledge about scientific and technological topics for the purpose of uncovering and enabling development of valuable new products, processes, and services. Under both models, R\&D differs from the vast majority of a company's activities which are intended to yield nearly immediate profit or immediate improvements in operations and involve little uncertainty as to the return on investment (ROI). The first model of R\&D is generally staffed by engineers while the second model may be staffed with industrial scientists. R\&D activities are carried out by corporate or governmental entities. 
Collaboration/partnerships. Collaboration is working together to achieve a goal. It is a recursive process where two or more people or organizations work together to realize shared goals, this is more than the intersection of common goals seen in co-operative ventures, but a deep, collective determination to reach an identical objective-for example, an intriguing (improper synthesis?) endeavor that is creative in nature-by sharing knowledge, learning and building consensus. Most collaboration requires leadership, although the form of leadership can be social within a decentralized and egalitarian group. In particular, teams that work collaboratively can obtain greater resources, recognition, and reward when facing competition for finite resources. Collaboration is also present in opposing goals exhibiting the notion of adversarial collaboration, though this is not a common case for using the word.

Partnerships exist within, and across sectors. Non-profit, religious, and political organizations may partner together to increase the likelihood of each achieving their mission and to amplify their reach. In what is usually called an alliance, governments may partner to achieve their national interests, sometimes against allied governments who hold contrary interests. In education, accrediting agencies increasingly evaluate schools by the level and quality of their partnerships with other schools and a variety of other entities across societal sectors. Partnerships also occur at personal levels, such as when two or more individuals agree to domicile together, while other partnerships are not only personal but private, known only to the involved parties.

Regulatory approval. Written consent by a regulatory body to proceed with a requested activity, without any way diminishing the applicant's obligation to meet the standard or specified requirements. Approval may take the form of certification, licensing, or registration, and it is sometimes used as an alternative term for authorization.

Labor market. Labor markets may be local or national (even international) in their scope and are made up of smaller, interacting labor markets for different qualifications, skills, and geographical locations. They depend on exchange of information between employers and job seekers about wage rates, conditions of employment, level of competition, and job location.

Service pipeline. The nominal market in which workers find paying work, employers find willing workers, and wage rates are determined. Service pipeline is the concept that defines the variety of services that are currently under development in the service portfolio. The service pipeline is a future based concept that defines the strategic future direction for the service provider. As part of the entire service portfolio, services are taken from the pipeline and put into the service catalog. The service transition phases these pipeline services into operation. The pipeline is a good indicator on the overall health of the service provider, as it shows the services that are under development for customers or markets.

Economies of scale. In microeconomics, economies of scale are the cost advantages that an enterprise obtains due to expansion. There are factors that cause a producer's average cost per unit to fall as the scale of output is increased. "Economies of scale" is a long run concept and refers to reductions in unit cost as the size of a facility and the usage levels of other inputs increase. More simply put, when more goods can be produced on a larger scale with lower costs, economies of scale is said to be achieved. The economic concept dates back to Adam Smith and the idea of obtaining larger production returns through the use of division of labor. Diseconomies of scale is the opposite.

Cluster partnerships. A small group of partnerships presents the involved parties with special challenges that must be navigated unto agreement. Overarching goals, levels of give-and-take, areas of responsibility, and 
lines of authority and succession, how success is evaluated and distributed, and often a variety of other factors must all be negotiated. Once agreement is reached, the partnership is typically enforceable by civil law, especially if well documented. Partners who wish to make their agreement affirmatively explicit and enforceable typically draw up articles of Partnership. It is common for information about formally partnered entities to be made public, such as through a press release, a newspaper ad, or public records laws.

Regulatory environment. A regulatory environment consists of laws and regulations that have been developed by federal, state, and local governments in order to exert control over business practices.

\section{External Factors}

Knowledge creation. Formation of new ideas through interactions between explicit and tacit knowledge in individual human minds. As defined by Ikujiro Nonaka, it consists of socialization (tacit to tacit), externalization (tacit to explicit), combination (explicit to explicit), and internalization (explicit to tacit).

Technology transfer. Technology transfer also called transfer of technology (TOT) and technology commercialisation, is the process of transferring skills, knowledge, technologies, methods of manufacturing, and samples of manufacturing and facilities among governments or universities and other institutions to ensure that scientific and technological developments are accessible to a wider range of users who can then further develop and exploit the technology into new products, processes, applications, materials, or services. It is closely related to (and may arguably be considered a subset of) knowledge transfer. Some also consider technology transfer as a process of moving promising research topics into a level of maturity ready for bulk manufacturing or production. Technology brokers are people who discovered how to bridge the disparate worlds and apply scientific concepts or processes to new situations or circumstances. A related term, used almost synonymously, is "technology valorisation”. While conceptually, the practice has been utilized for many years (in ancient times, Archimedes was notable for applying science to practical problems), the present-day volume of research, combined with high-profile failures at Xerox PARC and elsewhere, has led to a focus on the process itself.

Commercialization. The process or cycle of introducing a new product or production method into the market. The actual launch of a new product is the final stage of new product development, and the one where the most money will have to be spent for advertising, sales promotion, and other marketing efforts. Commercialization is often confused with sales, marketing, or business development. The commercialization process has three key aspects: 1) the funnel. It is essential to look at many ideas to get one or two products or businesses that can be sustained long-term, 2) it is a stage-wise process and each stage has its own key goals and milestones, and 3) it is vital to involve key stakeholders early, including customers.

Cluster \& networks. Clusters are geographically close groups of interconnected companies and associated institutions in a particular field, linked by common technologies and skills. They normally exist within a geographic area where ease of communication, logistics, and personal interaction is possible. Clusters are normally concentrated in regions and sometimes in a single town. However, personal network is a set of human contacts known to an individual, with whom that individual would expect to interact at intervals to support a given set of activities. Personal networks are intended to be mutually beneficial-extending the concept of teamwork beyond the immediate peer group. The term is usually encountered in the workplace, though it could apply equally to other pursuits outside work. Personal networking is the practice of developing and maintaining a personal network, which is usually undertaken over an extended period. 


\section{Payoff Matrix}

A payoff matrix is a decision analysis tool that summarizes pros and cons of a decision in a tabular form. It lists payoffs (negative or positive returns) associated with all possible combinations of alternative actions (under the decision maker's control) and external conditions (not under decision maker's control). The payoff matrix is an expression of the First Law of Decision Science. Each row represents one action that the decision maker might or might not freely choose to perform; each column represents a possible state of nature. At the time the decision must be made, the decision maker assumes that one of the columns represents the actual decision situation, but he or she does not know which column is the correct one. The cells of the matrix represent payoffs that the decision maker would receive if he or she chose the action represented by a particular row and the actual state of nature was the one represented by a particular column.

\section{Discussion}

The proposed model presented here provides an overview of the value cluster model of logistics service providers by considering mutual benefit, mutual relationship, and mutual satisfaction with game theory. These relations between variables will be examined in the exemplary case study, and any results will be further discussed to re-develop this integrated model. It should, however, be noted that this model should not be considered as a definitive method of the value cluster developed for all parties of logistics service providers. It seems that previous research has not yet defined such a method. This theoretical method is an initial attempt, which will be revised in the discussion of this thesis. The aim of the method development is to ensure that it may be used as a measurement of mutual benefit, mutual relationship, and mutual satisfaction. Also, this thesis used a quantitative, descriptive survey design. Two questionnaires were administered to collect the data from a convenient sample of 32 subjects. The questionnaires had both closed and open-ended questions. The sample characteristics included at least a manager or supervisor of logistics or transport companies, and were willing to participate. Consent was obtained from the subjects themselves. Questionnaires were distributed to subjects to ensure validity. Reliability and validity were further increased by pretesting the questionnaires.

\section{References}

Aumann, R. J., \& Shapley, L. S. (1974). Values of non-atomic games. Princeton, PA: Princeton University Press.

Cournot, A. A. (1838). Recherches sur les principles mathematiques de la théorie des richesses. Libraire des Sciences Politiques et Sociales. Paris: M. Rivière \& C.ie.

Edgeworth, F. Y. (1881). Mathematical psychics. London: Kegan Paul.

Farquharson, R. (1969). Theory of voting. Blackwell (Yale U.P. in the U.S.).

Harsanyi, J. C. (1974). An equilibrium point interpretation of stable sets. Management Science, 20(11), 1472-1495.

Levinger, G. (1983). Development and change. In H. H. Kelley, E. Berscheid, A. Christensen, J. H. Harvey, T. L. Huston, G. Levinger, E. McClintock, and L. A. Peplau (Eds.), Close relationships (pp. 315-359). New York: W.H. Freeman and Company.

Luce, R. D., \& Raiffa, H. (1957). Games and decisions: Introduction and critical survey. New York: Wiley.

Maynard Smith, J. (1982). Evolution and the theory of games. Cambridge University Press, ISBN 978-0-521-28884-2.

Maynard Smith, J., \& Price, G. R. (1973). The logic of animal conflict. Nature, 246(5427), 15-18.

Nash, J. (1950). Equilibrium points in n-person games. Proceedings of the National Academy of Sciences of the United States of America, 36(1), 48-49.

Duncan Luce, R., \& Raiffa, H. (1989). Games and decisions: Introduction and critical survey. New York: Dover Publications.

Shapley, L. S. (1953). Stochastic games. Proceedings of National Academy of Science, 39, 1095-1100.

Ventac Partners. (2011). Value from cluster formation. Retrieved from http://www.ventac-partners.com/biotech_cluster_development.html 
von Neumann, J. (1928). Zur theorie der gesellschaftsspiele. Mathematische Annalen, 100(1), 295-320. English translation: On the theory of games of strategy. In A. W. Tucker and R. D. Luce (Eds.). (1959). Contributions to the Theory of Games, 4, 13-42.

von Neumann, J., \& Morgenstern, O. (1944). Theory of games and economic behavior. Princeton, PA: Princeton University Press. Wikipedia. (2010). Third Party Logistics Service Provider.

Zermelo, E. (1913). Über eine anwendung der mengenlehre auf die theorie des schachspiels. Proceedings from The Fifth International Congress of Mathematicians 2, pp. 501-504. 